Revista Perspectivas Online: Biológicas \& Saúde Abril de 2019, Vol.9, no 29, p.1-10 ISSN: 2236-8868 (Online)

DOI: $10.25242 / 886892920191360$

\title{
EFEITOS DO DECANOATO DE NANDROLONA SOBRE PARÂMETROS FISIOPATOLÓGICOS DE FIGADO E RINS DE RATOS WISTAR
}

\author{
Beatriz Baldo de Almeida ${ }^{1}$, Franciele Januário de Lima ${ }^{1 *}$, Letícia Cristina Vellozo \\ Correia ${ }^{1}$, Loreane Aparecida Spirlandelli da Costa ${ }^{1} \&$ Ana Rosa Crisci ${ }^{1}$
}

\section{RESUMO}

ALMEIDA, B.B.; LIMA, F.J.; CORREIA, L.C.V.; COSTA, L.A.S. \& CRISCI, A.R. Efeitos do decanoato de nandrolona sobre parâmetros fisiopatológicos de figado e rins de ratos wistar Perspectivas Online: Biológicas \& Saúde. v. 9, n 29, p.1-10, 2019.

Os esteroides anabólicos androgênicos (EAA) são derivados sintéticos da testosterona que há muito tempo vem sendo discutidos na área científica. $\mathrm{O}$ uso sem fins terapêuticos vem expandindo em meio à população jovem, que utiliza superdoses a fim de aprimorar o desempenho atlético, gerando assim um problema de saúde pública. Deste modo, é imprescindível investigar as alterações metabólicas relacionadas ao consumo exacerbado. O objetivo do estudo foi analisar os efeitos adversos causados pelo Decanoato de Nandrolona na estrutura histológica e função hepática e renal de ratos machos da linhagem Wistar. Vinte ratos adultos foram divididos em dois grupos: tratamento (5 $\mathrm{mg} / \mathrm{kg}$ de Decanoato de Nandrolona) e controle ( $5 \mathrm{mg} / \mathrm{kg}$ de Óleo de Amendoim), e receberam as substâncias por via intramuscular duas vezes por semana, durante oito semanas consecutivas. Realizou-se análise histopatológica do fígado e rins e dosagens bioquímicas de aspartato aminotransferase (AST), alanina aminotransferase (ALT), creatinina e ureia. Os resultados demonstraram alterações na estrutura hepática, caracterizadas por uma intensa congestão vascular sinusoidal e central, além de áreas hemorrágicas intra e extra glomerulares no parênquima do córtex renal. Os parâmetros bioquímicos ALT, creatinina e ureia, não apresentaram diferença significativa entre os grupos experimentais, apenas na dosagem de AST que observou-se uma redução significativa nos níveis séricos. Os dados obtidos evidenciam que o uso de Decanoato de Nandrolona promove alterações na morfologia do fígado e rins.

Palavras-chave: Decanoato de Nandrolona; Congestão vascular; Fígado; Rins. 
ABSTRACT

\begin{abstract}
Anabolic androgenic steroids (AAS) are synthetic derivatives of testosterone that have long been discussed in the scientific field. Non-therapeutic use has been expanding among young people, in which use overdoses to improve athletic performance, thus generating a public health problem. Therefore, it is indispensable to investigate metabolic changes related to exacerbated consumption. The objective of this study was to analyze the adverse effects caused by Nandrolone Decanoate on histological structure and function in hepatic and renal of male Wistar rats. Twenty adult male Wistar rats were divided into two groups: treatment (5 $\mathrm{mg} / \mathrm{kg}$ of Nandrolone Decanoate) and control $(5 \mathrm{mg} / \mathrm{kg}$ of Peanut Oil), which were given intramuscularly twice weekly during
\end{abstract}

eight consecutive weeks. Were performed histopathological analysis of the liver and kidneys and biochemical measurements of aspartate aminotransferase (AST), alanine aminotransferase (ALT), creatinine and urea. The results showed alterations in the hepatic structure, characterized by intense sinusoidal and central vascular congestion, as well as intra and extraglomerular hemorrhagic areas in the renal cortex parenchyma. The biochemical parameters ALT, creatinine and urea, didn't present significant difference between the experimental groups, only in the dosage of AST that was observed a significant reduction in serum levels. The data obtained, evidenced that the use of Nandrolone Decanoate promotes changes in the morphology of the liver and kidneys.

Keywords: Nandrolone Decanoate; Vascular congestion; Liver; Kidneys.

\footnotetext{
${ }^{1}$ Centro Universitário Barão de Mauá - CBM - Rua Ramos de Azevedo, 423 - Jardim Paulista, Ribeirão Preto - SP, CEP:14090-180 - Brasil.

(*) e-mail: franciellejlima@ hotmail.com

Data de recebimento: 18/05/2018 Aceito para publicação: 28/03/2019
} 


\section{INTRODUÇÃOO}

Os Esteroides Anabólicos Androgênicos (EAA), são derivados sintéticos da testosterona que foram desenvolvidos com o objetivo de minimizar seus efeitos androgênicos e potencializar suas propriedades anabólicas (PEDROSO, 2014). O Decanoato de Nandrolona se configura como um dos EAA mais procurados no mundo (KUTSCHER; LUND; PERRY, 2002), já que a enzima 5 $\alpha$ redutase é responsável por converter a nandrolona na sua forma ativa e posteriormente originar um metabólito com baixa afinidade pelo receptor androgênico, assim, a nandrolona age mutuamente com os receptores presentes no tecido muscular produzindo respostas anabólicas mais satisfatórias (SILVA; DANIELSKI; CZEPIELEWSKI, 2002).

Dentre os efeitos tóxicos à saúde humana, pode-se destacar a hepatotoxicidade, que é decorrente da biotransformação dos EAA levando à alterações patológicas graves, como colestase progressiva, icterícia e peliose hepática. Além disso, o consumo prolongado destas substâncias está relacionado com o desenvolvimento de tumores hepáticos devido aos distúrbios hormonais, nos quais refletem no metabolismo intracelular. Em relação às complicações hepáticas mais relatadas, estão a hipertrofia, hiperplasia, lesões nos hepatócitos e discreta elevação nos níveis séricos de aspartato aminotransferase (AST) e alanina aminotransferase (ALT) (VIEIRA, 2003).

Também foi descrito por Luchi et al. (2015), que estas substâncias induzem o depósito de cálcio nos rins (nefrocalcinose) e formação de cálculos renais. Além destas complicações, há relatos de falência renal aguda, alterações tubulares e necrose tubular secundária à colestase, também causada por EAA (YOSHIDA et al., 1994).

Com a finalidade de aprofundar os estudos nesta temática e elucidar a ação do esteroide anabólico nas funções hepática e renal, o objetivo do estudo foi investigar os efeitos adversos que o Decanoato de Nandrolona pode causar na morfologia e função do tecido hepático e renal de ratos machos da linhagem Wistar.

\section{METODOLOGIA}

O presente trabalho tratou-se de uma pesquisa de natureza básica, com procedimento exploratório, experimental e de abordagem quantitativa. A pesquisa foi submetida à análise e aprovada pelo Comitê de Ética em pesquisa e experimentação animal (CEPan), do Centro Universitário Barão de Mauá, conforme o protocolo nº 282/17.

Foram utilizados 20 ratos Wistar machos com idade aproximada de 60 dias e pesando inicialmente 200 gramas. Os machos foram alojados em gaiolas individuais de polipropileno contendo cama de maravalha, grade superior e mantidos em ambiente controlado, com temperatura de 21 a $24^{\circ} \mathrm{C}$, recebendo água e ração própria suficiente para suprir a demanda energética durante todo o período experimental.

O estudo teve duração de 56 dias e os animais foram divididos em 2 grupos, contendo 10 ratos cada: grupo de tratamento $(5 \mathrm{mg} / \mathrm{kg}$ de Decanoato de Nandrolona diluído em $0,4 \mathrm{~mL}$ de óleo de amendoim) e grupo controle ( $5 \mathrm{mg} / \mathrm{kg}$ de óleo de amendoim). As aplicações foram realizadas por via intramuscular, 2 vezes na semana, sempre às segundas e quintas-feiras, entre às $11 \mathrm{~h} 00$ e $11 \mathrm{~h} 30$. As doses foram calculadas antes de toda aplicação, a partir do peso do animal e volume prédeterminado de $0,125 \mathrm{~mL}$.

A escolha de $5 \mathrm{mg} / \mathrm{kg}$ de Decanoato de Nandrolona foi baseada nos estudos de Cardoso (2008) e Vieira et al. (2008), sendo considerada dose intermediária (VIEIRA et al., 2008). Segundo Norton, Trifunovic e Woodiwiss (2000), essa dose é equivalente às que normalmente são utilizadas

Persp. online: biol. \& saúde, Campos dos Goytacazes, 29 (9), 1-10, 2019 
em academias de ginástica.

No final do experimento os animais foram eutanasiados com dose letal dos anestésicos cloridrato de ketamina $(100 \mathrm{mg} / \mathrm{kg})$, cloridrato de xilazina $(6 \mathrm{mg} / \mathrm{kg})$ e tiopenthal sódico $(40 \mathrm{mg} / \mathrm{kg})$.

Após o sacrifício foi coletado $10 \mathrm{~mL}$ de sangue pelo método de punção cardíaca, no qual foi destinado para as dosagens bioquímicas de AST, ALT, creatinina e ureia.

Nas análises bioquímicas, foram utilizados kits comerciais Dialab ${ }^{\circledR}$ para as dosagens de AST, ALT, creatinina e ureia pelo método de espectrofotometria. Segundo Chaves (2005), é importante um planejamento estatístico para maior confirmação das hipóteses, portanto, as dosagens desta pesquisa foram realizadas em triplicatas e para cada variável, foram calculados a média e o erro-padrão. Os grupos foram comparados por meio do teste paramétrico t-Student bilateral não-pareado (para as variáveis ALT, AST e ureia) e do teste não paramétrico MannWhitney (para a variável creatinina). O nível de significância adotado foi $\mathrm{p} \leq 0,05$.

$\mathrm{Na}$ laparotomia exploratória foram coletados $\mathrm{o}$ fígado e rins para avaliações histopatológicas, os quais foram fixados em formaldeído a 10\% no tempo mínimo de 48 horas e em seguida foram submetidos ao procedimento histológico, obtendo-se secções 06 micrômetros de espessura, coradas com hematoxilina-eosina (HE). Após o processamento do material, as lâminas foram analisadas no microscópio Nikon Eclipse $E 100^{\circledR}$ e as fotomicrografias obtidas em fotomicroscópio HD Lite $1080 \mathrm{P}^{\circledR}$.

\section{RESULTADOS E DISCUSSÃO}

\subsection{Avaliação fisiopatológica do fígado}

$\mathrm{Na}$ análise histopatológica do fígado do grupo controle (Figura 1A), observou-se que o parênquima hepático apresentou aspectos lobulares preservados, assim como a veia central e os cordões de hepatócitos.

Já nos animais do grupo tratado (Figura 1B), verificou-se áreas pouco preservadas, além de uma intensa congestão vascular sinusoidal e central, concordando com o estudo de Vieira (2003), que também demonstrou um aumento de canalículos e grandes vasos congestos por hemácias, causados pela dose intermediária, sendo que o aumento da dose pode levar a um quadro de colestase intra-hepática pura.

O aumento do volume do fígado, devido à hiperplasia dos hepatócitos (KARBALAYDOUST; NOORAFSHAN, 2009), dilatações nas veias centrais dos lóbulos e congestão parcial na cápsula fibrosa perivascular (TAKAHASHI; TATSUGI; KOHNO, 2004), também se configuram como alterações morfológicas resultantes do uso de Decanoato de Nandrolona. 

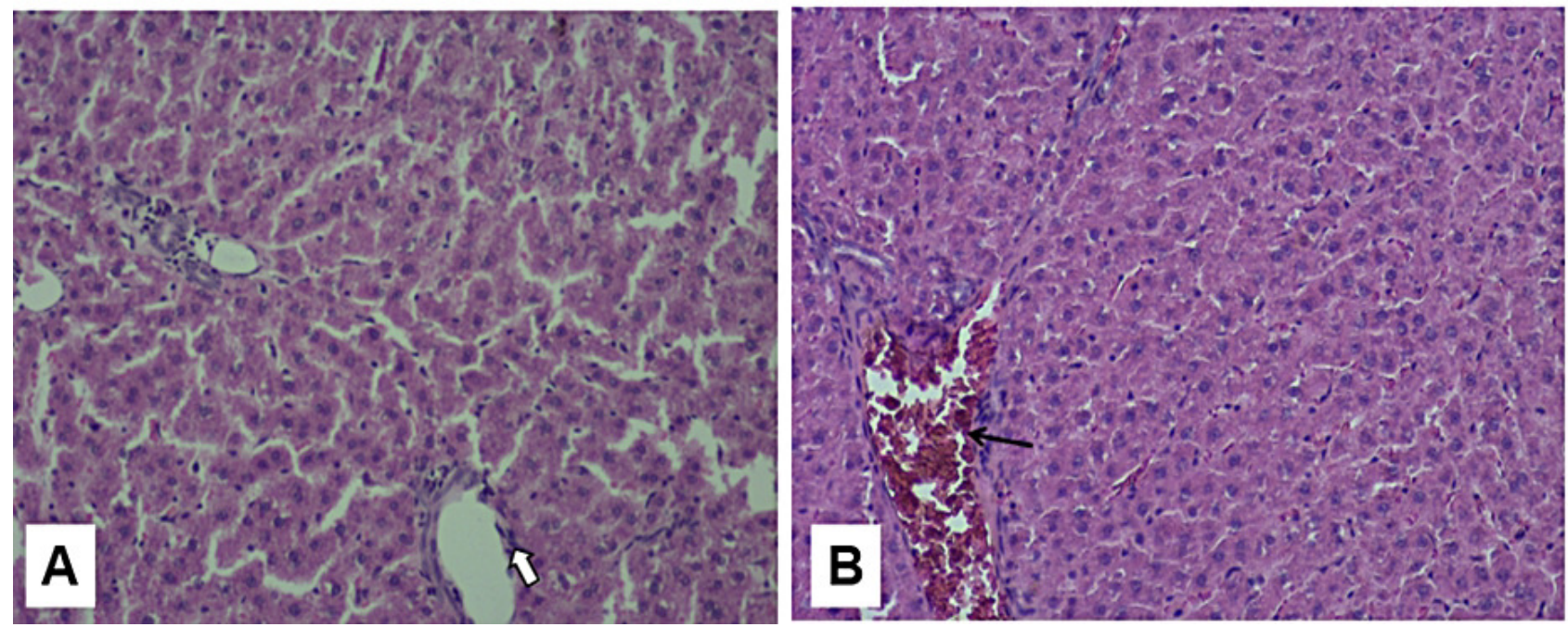

Figura 1- Fotomicrografias do fígado dos grupos experimentais. Figura A: grupo controle, com parênquima hepático normal e apresentando veia central preservada (seta branca). Figura B: grupo tratado apresentando uma intensa congestão vascular sinusoidal e central (seta preta). Aumento $100 \mathrm{X}$.

Em relação aos níveis séricos de ALT, não houve diferença estatística entre os grupos (Figura 2), mostrando que os dados estão de acordo com estes referenciais bibliográficos, onde não há relatos de elevação nesta dosagem enzimática (FRANKENFELD et al., 2014; FARIA et al., 2012; KALININE, 2011; VIEIRA, 2003; GAYOTTO e ALVES, 2001).

Já nos níveis séricos de AST houve diminuição (Figura 3), demostrando uma diferença significativa entre o grupo tratado e controle $(\mathrm{p}=0,0002)$, o que diverge do estudo de Alén (1985), que descreveu um aumento significativo de AST no grupo que recebeu esteroides, porém ele sugere que esta elevação seja de origem muscular e não hepática, devido ao treino excessivo que os participantes realizavam.

Comparando com os resultados de Samieinasab et al. (2015), o Decanoato de Nandrolona também causou a redução nos níveis de AST, mas houve aumento nos níveis de ALT.

Em contradição com os dados do presente estudo, Venâncio et al. (2010), constataram aumento significativo nas concentrações dessas enzimas entre os grupos estudados. O que também foi observado por VIEIRA et al. (2008) que relatam um aumento dose-dependente nos níveis séricos de ALT, AST e fosfatase alcalina em ratos, após a administração de Decanoato de Nandrolona. Além disso, sugeriram que doses supra-fisiológicas do esteroide são potencialmente deletérias ao fígado, induzindo um quadro clínico de fibrose.

Não foi possível estabelecer os motivos pelos quais o Decanoato de Nandrolona causou tanto redução, como aumento nos níveis de AST nos diversos estudos. Porém, foi possível observar que o esteroide possui uma ação negativa sobre as enzimas hepáticas.

A maioria dos efeitos colaterais relacionados ao uso abusivo de esteroides sintéticos está relacionada ao sistema hepático, devido a sua função de metabolização, estes efeitos podem evoluir desde pequenos distúrbios até o câncer (YOSHIDA et al., 1994).

A determinação dos níveis das transaminases séricas é geralmente considerada de grande valor para detectar efeitos tóxicos no fígado. No entanto, a interpretação deve ser feita usando duas 
ou mais enzimas (VIEIRA et al., 2008). Portanto, baseando-se somente nos níveis séricos das enzimas, não é conclusivo o quadro de hepatotoxicidade, porém quando correlacionamos os parâmetros bioquímicos do presente estudo, com a análise histopatológica, sugere-se que existe um processo inicial de lesão tecidual, podendo levar à alterações patológicas graves, caso o tratamento com o esteroide tivesse sido prolongado.

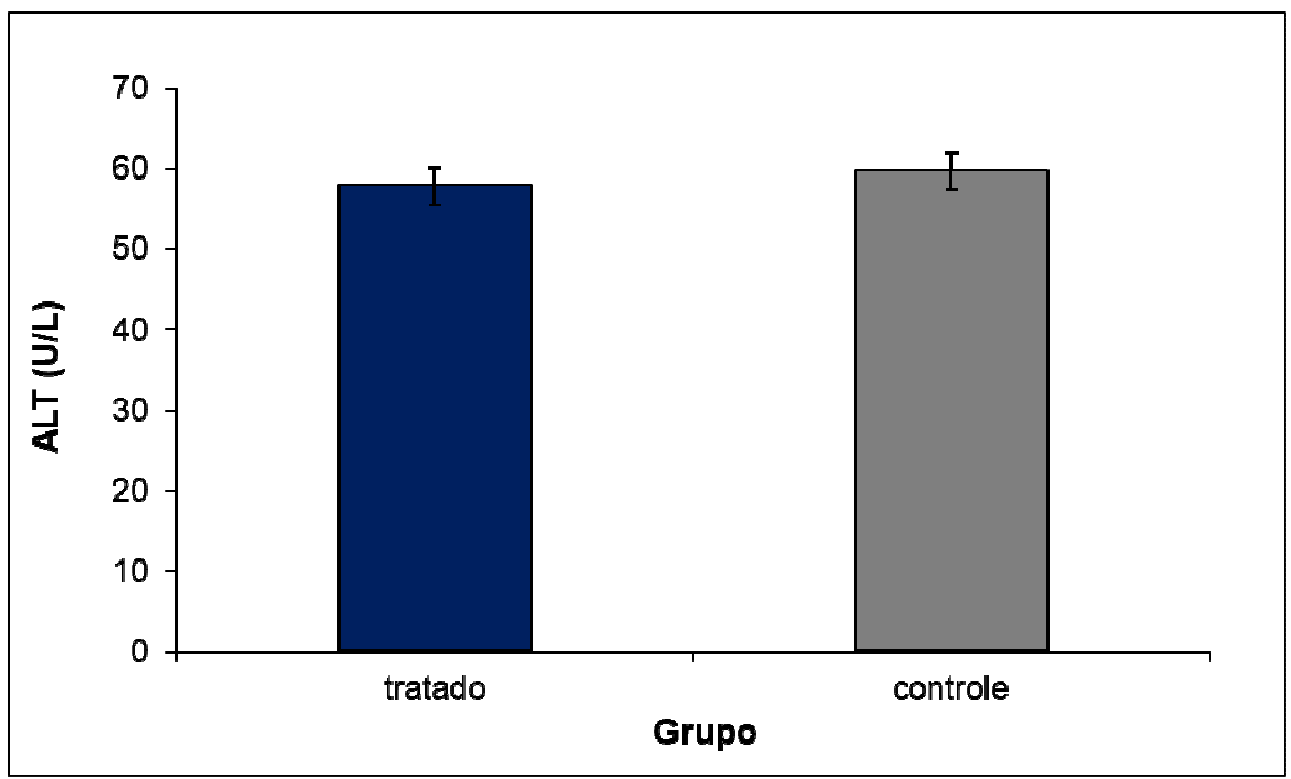

Figura 2 - Média dos níveis séricos de ALT

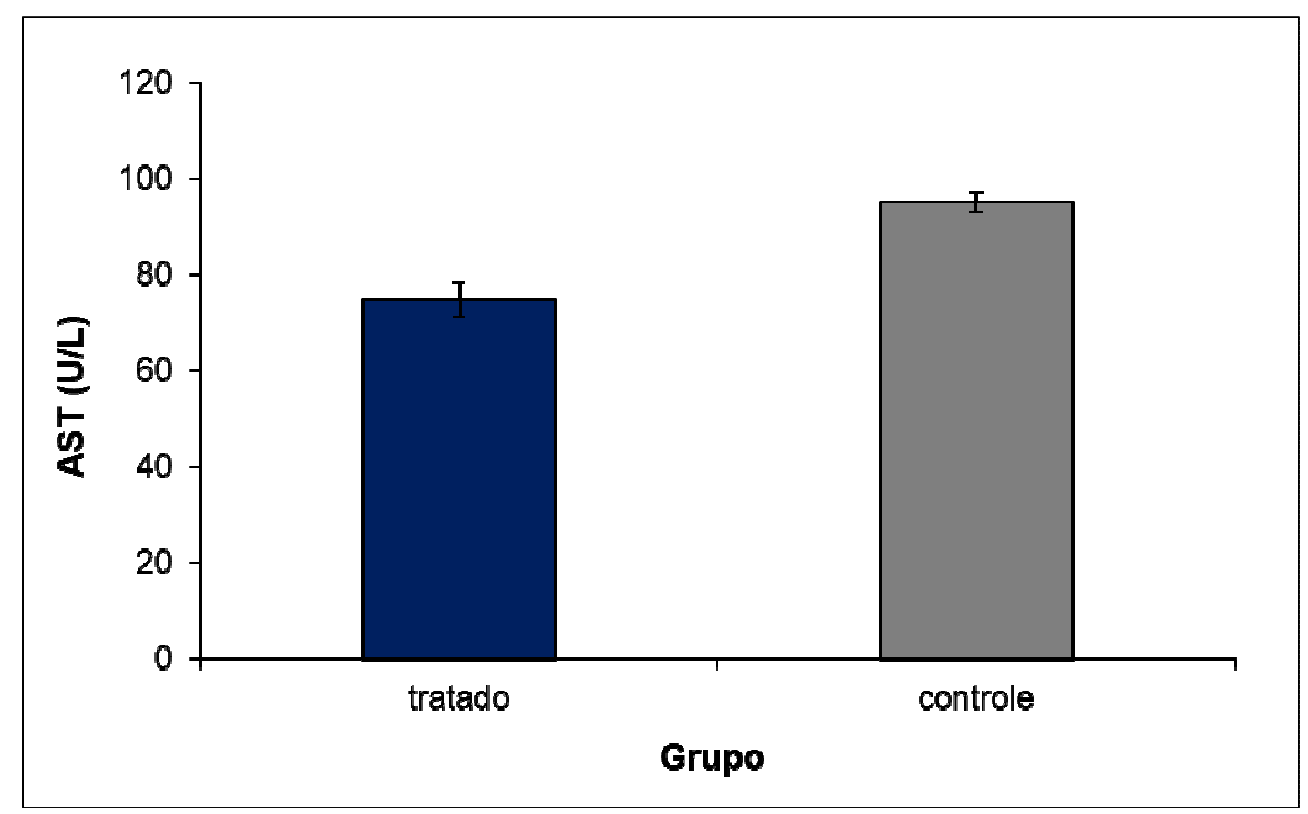

Figura 3 - Média dos níveis séricos de AST

\subsection{Avaliação fisiopatológica dos rins}

A funcionalidade dos rins não foi afetada com o tratamento, visto que as dosagens séricas de creatinina e ureia, nas quais são parâmetros responsáveis pela avaliação do metabolismo renal, não evidenciaram diferença significativa entre os grupos experimentais (Figuras 4 e 5). Concordando 
com o estudo de Kalinine (2011), onde não foi observado alterações nestes parâmetros.

O aumento da dosagem sérica de creatinina e ureia após o uso de Decanoato de Nandrolona, foi demonstrado por Tsitsimpikou et al. (2016), evidenciando um efeito na função renal. Uma hipótese que pode ser desenvolvida a partir desses dados, é a de que a dose intermediária usada, a quantidade de aplicações e o período experimental do presente estudo, não leva à alterações nestes parâmetros bioquímicos.

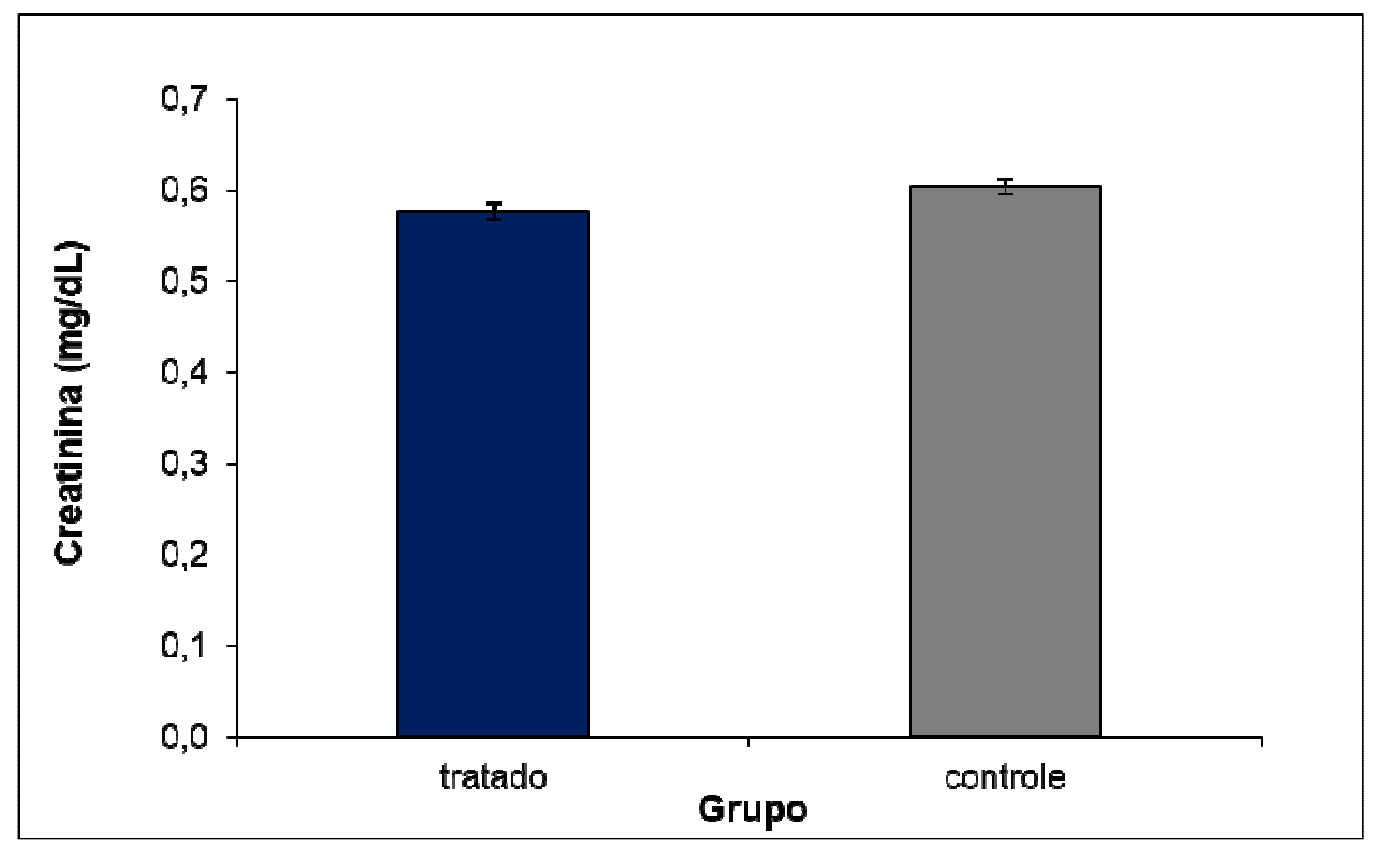

Figura 4 - Média dos níveis séricos de creatinina

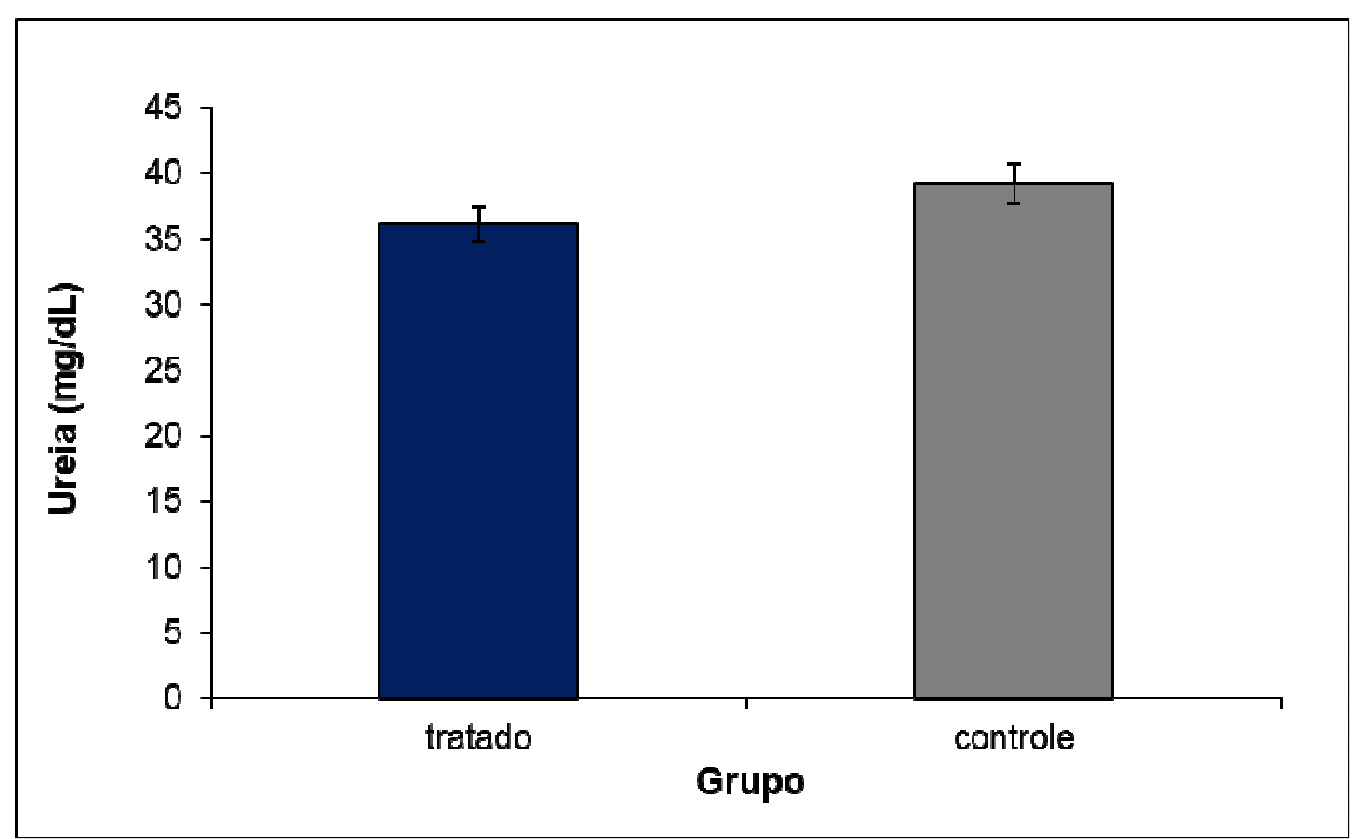

Figura 5 - Média dos níveis séricos de ureia

A análise histológica do grupo tratado (Figura 6B) demonstrou áreas hemorrágicas intra e extra glomerulares com acentuado bloqueio vascular intertúbulos no parênquima do córtex renal, enquanto que, nos rins do grupo controle (Figura 6A) observou-se sem alterações morfológicas, 
com glomérulos renais e estruturas tubulares apresentando núcleos com cromatina finamente granular e homogênea.

A congestão vascular, também foi relatada por Tsitsimpikou et al. (2016), além disso, a morfologia renal do grupo de animais tratado também apresentou fibrose e inflamação focal.

Luchi et al. (2015), propõe que a nefrocalcinose é um mecanismo adicional de lesão dos EAA, em seu estudo de caso, a biópsia renal mostrou diversos focos de calcificação, nefroesclerose e necrose tubular, em um paciente que fazia o uso de Decanoato de Nandrolona.

Outras anormalidades na morfologia renal que já foram relatadas devido ao consumo deste esteróide, incluem o aumento significativo do peso dos rins e volume do cortéx e túbulos contorcidos proximal e distal (HOSEINI et al., 2009). Tofighi et al. (2018), também demonstra alterações histológicas, como fibrose e proliferação de células do tecido renal.

Esses achados indicam que o Decanoato de Nandrolona induz anormalidades renais, evidenciando os resultados morfológicos observados no presente estudo. Em concordância com este fato, Tsitsimpikou et al. (2016), sugere que o uso a longo prazo, causa alterações tanto na estrutura, como na função renal.
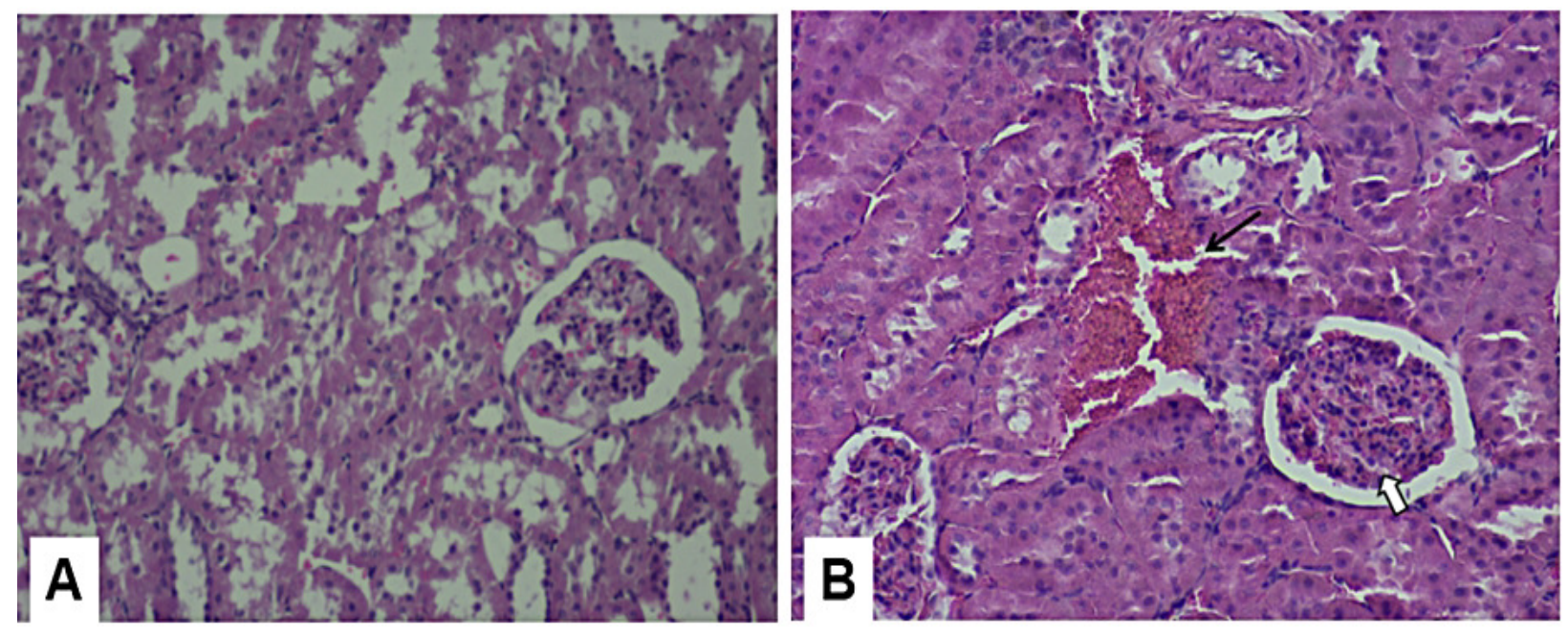

Figura 6 - Fotomicrografias dos rins dos grupos experimentais. Figura A: grupo controle com parênquima do córtex renal com aspectos normais. Figura B: grupo tratado apresentado parênquima do córtex renal com áreas hemorrágicas intra glomerulares (seta branca) e extra glomerulares (seta preta). Aumento 100X.

Por meio das análises histopatológicas e dados da literatura, foi possível observar que a congestão vascular ocorre tanto na estrutura hepática, quanto na renal, constatando assim, um efeito característico decorrente do uso de Decanoato de Nandrolona. Para explicar melhor estes mecanismos, é necessário a realização de estudos que investiguem outros parâmetros hepáticos e renais, para se obter uma associação mais evidente sobre esta alteração morfológica.

\section{CONCLUSÕES}

O presente estudo pode constatar que o uso de Decanoato de Nandrolona na dose de $5 \mathrm{mg} / \mathrm{kg}$, não provocou aumento nos níveis séricos de ALT, creatinina e ureia, porém causou uma 
redução significativa nos níveis séricos de AST. Além disso, modificou consideravelmente a morfologia do fígado e rins, levando à um quadro de congestão vascular. Isso demonstra um eminente perigo à saúde dos usuários, uma vez que os parâmetros bioquímicos não revelaram alterações hepáticas e renais, mascarando assim os efeitos do esteroide no fígado e rins.

Deste modo, é importante aprofundar os estudos nessa temática, com a finalidade de se obter novas informações, não apenas dos parâmetros pesquisados, mas de todos os sistemas orgânicos.

\section{REFERÊNCIAS}

ALÉN, M. Androgenic steroid effects on liver and red cells. Brit J Sports Med, v.19, p.15-20, 1985.

CHAVES, J.B.P. Planejamento Estatístico De Experimentos Científicos. 2005. Disponível em: <http://www.minaslac.dta.ufv.br/artigos/planestat.htm>. Acesso em: 03 abr. 2017.

FARIA, P.P.O. et al. Avaliação de parâmetros físicos e biológicos de ratos Wistar após administração de decanoato de nandrolona. Acta Biomedica Brasiliensia, Itaperuna, v. 3, n. 2, p.2637, dez. 2012.

FRANKENFELD, S. P. et al. The Anabolic Androgenic Steroid Nandrolone Decanoate Disrupts Redox Homeostasis in Liver, Heart and Kidney of Male Wistar Rats. Plos One, Kkk, v. 9, n. 9, p.18, set. 2014.

GAYOTTO, L.C.C.; ALVES, V.A.F. Doenças do fígado e vias biliares. São Paulo: Atheneu, 2001.

HOSEINI, L. et al. Nandrolone decanoate increases the volume but not the length of the proximal and distal convoluted tubules of the mouse kidney. Micron, Kkkk, v. 40, n. 2, p.226-230, fev. 2009.

KALININE, E. Efeitos comportamentais, neuroquímicos e metabólicos do tratamento com decanoato de nandrolona em camundongos. 2011. 63 f. Dissertação (Mestrado) - Curso de Bioquímica, Universidade Federal do Rio Grande do Sul, Porto Alegre, 2011.

KARBALAY-DOUST, S.; NOORAFSHAN, A. Stereological study of the effects of nandrolone decanoate on the mouse liver. Micron, v. 40, n. 4, p.471-475, jun. 2009.

LUCHI, W. M. et al. Nefrocalcinose associada ao uso de esteroide anabolizante. Jornal Brasileiro de Nefrologia, São Paulo, v. 37, n. 1, p.135-140, mar. 2015.

PEDROSO, R. C. Esteroides Anabólicos Androgênicos. In: OGA, S.; CAMARGO, M.M.A.; BATISTUZZO, J. A. O. Fundamentos de Toxicologia. 4. ed. São Paulo: Atheneu, 2014. Cap. 62. p. 557-568.

SAMIEINASAB, M. R. et al. Influence of nandrolone decanoate administration on serum lipids and liver enzymes in rats. Arya Atheroscler, Ffff, v. 11, n. 4, p.256-260, 2015.

TAKAHASHI, M.; TATSUGI, Y.; KOHNO, T. Endocrionological and pathological effects of anabolic-androgenic steroids in male rats. Endocrine Journal, Tóquio, v. 51, n. 4, p.425-434, 2004.

TOFIGHI, A. et al. Nandrolone administration with or without strenuous exercise promotes overexpression of nephrin and podocin genes and induces structural and functional alterations in the kidneys of rats. Toxicology Letters, Kkkk, v. 282, n. 5, p.147-153, jan. 2018.

TSITSIMPIKOU, C. et al. Nephrotoxicity in rabbits after long-term nandrolone decanoate administration. Toxicology Letters, L1ll, v. 259, n. 30, p.21-27, set. 2016.

VENÂNCIO, D.P; NÓBREGA, A.C.L; TUFIK, S; MELLO, M.T. Avaliação descritiva sobre o uso de esteroides anabolizantes e seu efeito sobre as variáveis bioquímicas e neuroendócrinas em indivíduos que praticam exercício resistido. RevBrasMed Esporte, v.16, p.191-95, 2010. 
VIEIRA, R. P. et al. Dose-Dependent Hepatic Response to Subchronic Administration of Nandrolone Decanoate. Medicine \& Science In Sports \& Exercise, v. 40, n. 5, p.842-847, 2008.

VIEIRA, R.P. Efeitos do decanoato de nandrolona sobre o fígado de ratos. 2003. 59 f. Dissertação (Mestrado) - Curso de Ciências Biológicas, Universidade do Vale do Paraíba, São José dos Campos, 2003.

YOSHIDA, E.M. et al. At what price, glory? Severe cholestasis and acute renal failure in an athlete abusing stanozolol. Canadian Medical Association Journal, Toronto, v. 151, n. 6, p.791-793, set. 1994. 